\title{
Global Perspective of the Vitamin D Status of African-Caribbean Populations: A Systematic Review and Meta-analysis
}

\author{
Rebecca M. Vearing ${ }^{1,2}{ }^{凶}$, Kathryn H. Hart $\mathbb{D}^{1}{ }^{1}$, Andrea L. Darling $\mathrm{ID}^{1}$, Yasmine Probst $\mathrm{ID}^{2,3}$, Aminat S. Olayinka ${ }^{1}$, Jeewaka Mendis ${ }^{4}$,
} Helena Ribeiro (D) ${ }^{5}$, Siddhartha Thakur (iD) ${ }^{6}$, Marcela Mendes (iD) ${ }^{1,7}$, Karen Charlton (iD ${ }^{2,3}$ and Susan A. Lanham-New (D) ${ }^{1}$

(c) The Author(s) 2021

BACKGROUND/OBJECTIVES: Vitamin D deficiency remains a global public health issue, particularly in minority ethnic groups. This review investigates the vitamin $\mathrm{D}$ status (as measured by $25(\mathrm{OH}) \mathrm{D}$ and dietary intake) of the African-Caribbean population globally. SUBJECTS/METHODS: A systematic review was conducted by searching key databases (PUBMED, Web of Science, Scopus) from inception until October 2019. Search terms included 'Vitamin D status' and 'African-Caribbean'. A random effects and fixed effects meta-analysis was performed by combining means and standard error of the mean.

RESULT: The search yielded 19 papers that included $n=5670$ African-Caribbean participants from six countries. A meta-analysis found this population to have sufficient $(>50 \mathrm{nmol} / \mathrm{L}) 25(\mathrm{OH}) \mathrm{D}$ levels at $67.8 \mathrm{nmol} / \mathrm{L}, 95 \% \mathrm{Cl}(57.9,7.6)$ but poor dietary intake of vitamin $\mathrm{D}$ at only $3.0 \mu \mathrm{g} /$ day, $95 \% \mathrm{Cl}(1.67,4.31)$. For those living at low latitudes 'insufficient' (as defined by study authors) $25(\mathrm{OH}) \mathrm{D}$ levels were found only in participants with type 2 diabetes and in those undergoing haemodialysis. Suboptimal dietary vitamin D intake (according to the UK recommended nutrient intake of $10 \mu \mathrm{g} / \mathrm{day}$ ) was reported in all studies at high latitudes. Studies at lower latitudes, with lower recommended dietary intakes (Caribbean recommended dietary intake: $2.5 \mu \mathrm{g} / \mathrm{day}$ ) found 'sufficient' intake in two out of three studies.

CONCLUSIONS: 25(OH)D sufficiency was found in African-Caribbean populations at lower latitudes. However, at higher latitudes, 25(OH)D deficiency and low dietary vitamin $D$ intake was prevalent.

European Journal of Clinical Nutrition (2022) 76:516-526; https://doi.org/10.1038/s41430-021-00980-9

\section{INTRODUCTION}

The majority of vitamin $D$ is derived from sunlight exposure, rather than food [1, 2]. When ultraviolet-B (UVB) radiation (wave length 290-315 nm) comes into contact with the skin, 7dehydrocholesterol (provitamin $D_{3}$ ) converts to vitamin $D_{3}$ (cholecalciferol) [3]. In total, $80-100 \%$ of vitamin D is synthesised in this way, with the remainder coming from dietary intake of food and/or supplements [4-7]. Vitamin D is naturally present in a limited number of foods including animal sources (cholecalciferol) such as oily fish, red meat, dairy and eggs and plant sources (ergocalciferol) such as UVB exposed mushrooms [3]. Vitamin D from food sources is absorbed and converted to 25hydroxyvitamin $\mathrm{D}[25(\mathrm{OH}) \mathrm{D}]$ in the liver, along with vitamin $\mathrm{D}_{3}$ from sunlight synthesis. $25(\mathrm{OH}) \mathrm{D}$ is the major circulating form of vitamin D. It can be used as a marker of vitamin D status, as it reflects the synthesis from sun exposure as well as from dietary intake [7]. In the kidneys, 25(OH)D is metabolised to the biologically active form of vitamin $\mathrm{D}, 1,25[\mathrm{OH}]_{2} \mathrm{D}$ (calcitriol) [8]. The main role of this active form is the maintenance of calcium homeostasis, and therefore, musculoskeletal health $[2,9]$. In addition, most cells in the body have a vitamin $D$ receptor, meaning that vitamin $D$ influences many biological pathways, and vitamin $\mathrm{D}$ deficiency is associated with disease states including certain cancers, type 2 diabetes mellitus (T2DM), multiple sclerosis, immune response and cardiovascular disease $[2,8,10-14]$. In this review, vitamin $D$ status will refer to $25(\mathrm{OH}) \mathrm{D}$, which is mainly from cutaneous synthesis. Dietary intake includes vitamin D sourced from both ergocalciferol and cholecalciferol.

Vitamin D synthesis is multifactorial, with both environmental and personal factors impacting on an individual's ability to synthesise vitamin D cutaneously, and to consume it through their diet. Low UVB exposure, which may relate to latitude, season, pollution or urbanisation, are key factors in vitamin $D$ synthesis $[7,15,16]$ while personal characteristics, including ethnicity, skin type, age and sun exposure habits, may lead to higher or lower vitamin $D$ synthesis [11]. Vitamin D deficiency may lead to rickets in children, or osteomalacia and osteoporosis in adults, as well as other non-bone related conditions [17].

Vitamin D deficiency remains a global public health issue, particularly in minority ethnic groups [18]. There is a lack of research investigating the vitamin $D$ status of the AfricanCaribbean (AfC) population globally. This population refers to those with African ancestry who migrated via the Caribbean, or those native to the Caribbean with African ancestry [19].

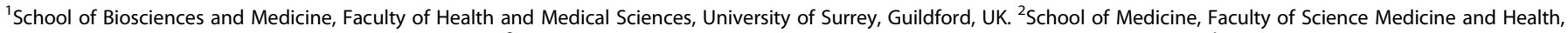

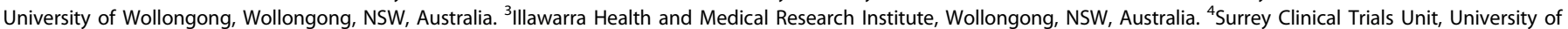

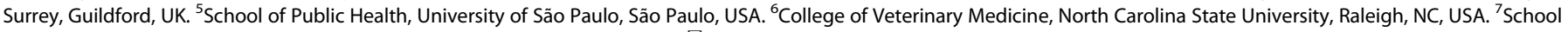
of Nutrition, Faculty of Health Sciences, University of Brasilia, Brasilia, Brazil. ${ }^{凶}$ email: rv00158@surrey.ac.uk 
This population has darkly pigmented skin, which reduces the capacity to synthesise vitamin D. This is because increased melanin content acts as a natural 'sunscreen' [11, 20].

AfC populations are known to have low levels of vitamin $D$ deficiency $[17,21]$. However, research to date has mostly been undertaken in countries with low latitudes and high year-round sun exposure. Migration away from the equator to higher latitudes, and thus reduced sun exposure, has had consequences for vitamin D concentration for populations with darker skin types $[3,11]$. Further, the ability to synthesise vitamin $D$ from sunlight is restricted to the summer months in countries higher than $37^{\circ} \mathrm{N}$ [22]. Vitamin D status in the winter months in those countries is reliant solely on dietary or supplemental intakes, which is often inadequate to meet requirements. Thus, it is likely that AfC people living at higher latitudes have a poorer vitamin $D$ status than those living closer to the equator. This hypothesis is partially supported by a review by Wacker et al. [11] that reported a significant inverse relationship between mean circulating 25(OH)D levels and latitude in European young adults. Whether these findings would translate to an AfC population is yet unknown.

This systematic review and meta-analysis characterises the current vitamin D status of AfC populations globally, residing at different latitudes and geographical regions, in order to identify clinical and public health need, as well as areas of future research. In particular, this review provides key data on vitamin D concentration in a variety of African-Caribbean populations, which will inform the development of policy as well as clinical decision making, globally.

\section{METHODS}

\section{Literature search}

A search for relevant literature was undertaken in October 2019 using the PUBMED, Web of Science and Scopus scientific databases. The following search including MeSH terms were used: (Vitamin D intake OR dietary vitamin D OR vitamin D supplement OR vitamin D consumption OR Vitamin D status OR vitamin D level OR 25(OH)D OR 25-hydroxy*) AND (African-Caribbean OR afroCaribbean OR African OR Caribbean). The literature search was not limited to a time period but included only human studies that were published in the English language (See Supplementary File Table 1 for the full search criteria).

\section{Eligibility criteria for inclusion and data extraction}

One author (RMV) screened the titles and abstracts of potential papers and then screened the full text papers for final inclusion. Additionally, a random sample (10\%) of both the abstracts and full text papers were cross-checked by a second author (ASO). Any discrepancies were deferred to a third party where required (ALD, $\mathrm{KHH}, \mathrm{SLN}$ ).

Papers that assessed vitamin D status as a primary outcome, either through dietary vitamin $D$ intake or serum $25(\mathrm{OH}) \mathrm{D}$ concentration, in an AfC population were included. Any human studies with a population described or self-identified as "AfricanCaribbean/Afro-Caribbean/Black Caribbean" were included, as well as studies with Caribbean populations of African ancestry. Those papers which did not specifically define an AfC population, or described their population as 'African-American' or 'African' were excluded [19]. All age and gender groups were included, including infants and pregnant women, as well as those with diagnosed disease states. Studies at low latitudes $\left(0-37^{\circ}\right.$ North and South) and high latitudes (37-90 North and South) were included. Reviews and conference abstracts were excluded.

At the first stage of screening, populations described as 'black' were included. At full text screening if a 'black' population referred to anything other than an AfC population, the paper was excluded. Papers with populations described as 'black', which included AfCs, were excluded if specific data for the primary

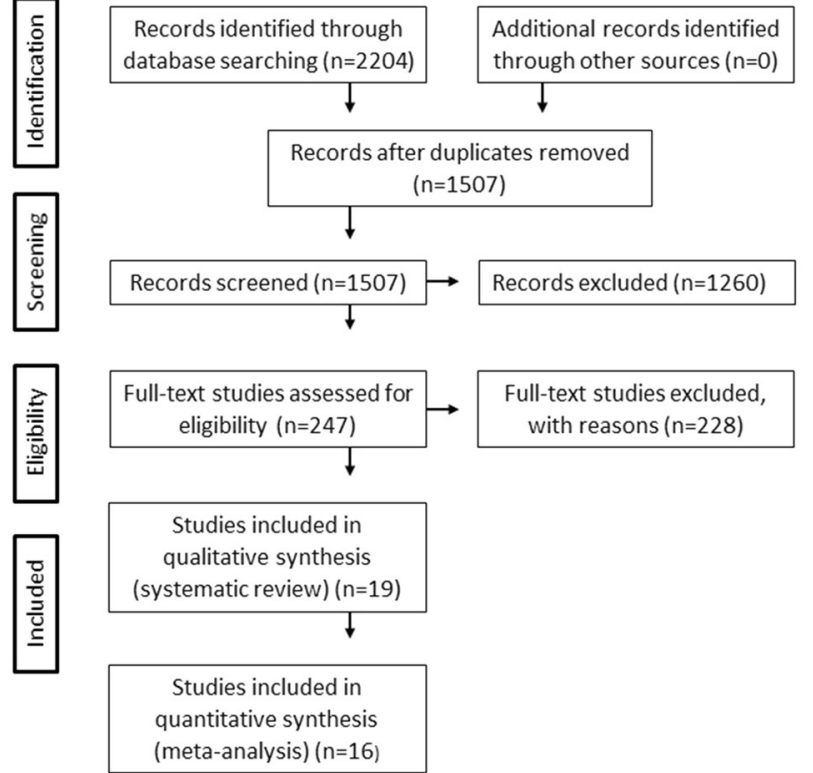

Fig. 1 PRISMA flow diagram showing study selectionAQ5 process [23]. PRISMA flow diagram summarising the results of the search and selection processes.

outcome had not been presented for the AfC participants alone. Study authors were contacted for further information regarding ethnicity, as required.

Information was extracted from the included studies to summarise the author and publication year, study design, latitude, population, primary outcomes and secondary outcomes. The actual data for relevant outcomes were also extracted. We followed the Preferred Reporting Items for Systematic Reviews and MetaAnalyses (PRISMA) [23] guidelines (See PRISMA checklist). The review was registered with PROSPERO number: CRD42019158108, https://www.crd.york.ac.uk/PROSPERO/.

\section{Data and statistical analysis}

A meta-analysis was performed, using the 'rmeta' package within R Studio [24], combining means and standard error of the mean (SEM), to obtain a pooled estimate. Studies were included in the meta-analysis if they provided adequate data in terms of means and SEM for vitamin D 25(OH)D concentration and/or vitamin $\mathrm{D}$ dietary intake. If this was not provided, authors were contacted to request further data. As required, SEM was calculated by dividing the standard deviation (SD) of the mean by the square root of the sample size. If only median and IQR were presented, then they were converted to mean and SD [25]. If sufficient data could not be obtained, the study was excluded from the meta-analysis [26, 27]. Random and fixed effects models were used, and heterogeneity was assessed $(p<0.05$ was considered as statistically significant heterogeneity). A sensitivity analysis was conducted by removing each study from the analysis in turn and inspecting effect size. A Pearson's correlation was conducted to assess the relationship between latitude and $25(\mathrm{OH}) \mathrm{D}$ concentration.

Methods for measuring vitamin D status, as well as the cut-offs used to define sufficiency and deficiency, differ in the literature. This review categorised vitamin $D$ cut-offs as: vitamin $D$ deficiency $(<25 \mathrm{nmol} / \mathrm{L})$ [22], insufficiency ( $>25-50 \mathrm{nmol} / \mathrm{L})$ [28] and sufficiency (>50 nmol/L) [28] (Supplementary File and Table 2). Recommended vitamin $D$ dietary intakes varied between the countries of the papers included in this review, with adults in the United Kingdom (UK) being recommended to consume $10 \mu \mathrm{g} / \mathrm{day}$ of vitamin D [22] while those in the Caribbean islands advised to 


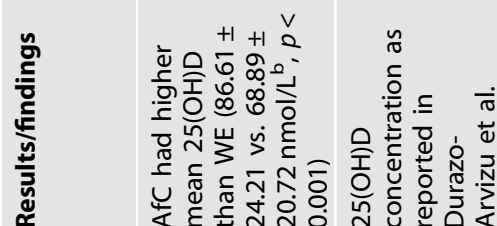

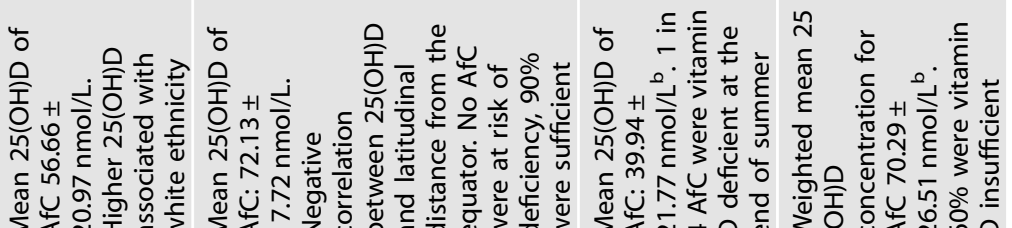

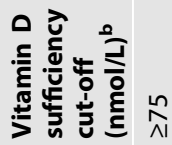

ํํ

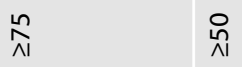

$\stackrel{n}{N}$



ㅇํํ

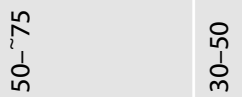

$\stackrel{n}{\hat{v}}$

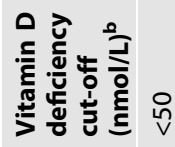

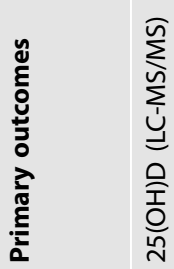

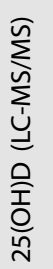

ใิ

ำ

$\stackrel{\text { v }}{v}$



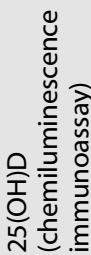

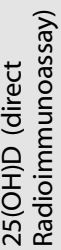

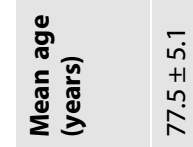

$-\bar{b}$
+1
+
$\dot{m}$

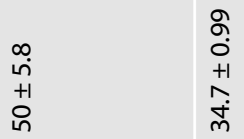

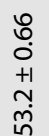

$\frac{5}{\frac{5}{6}}$

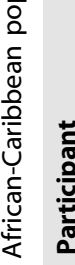
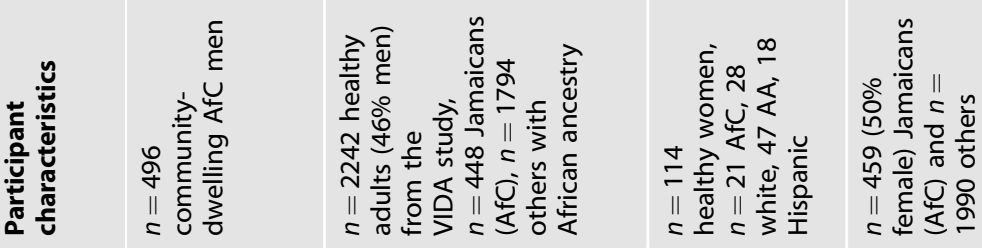

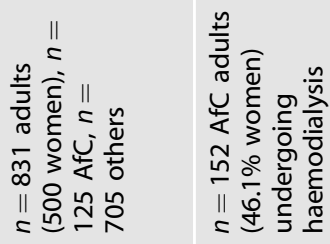

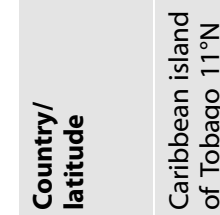

른
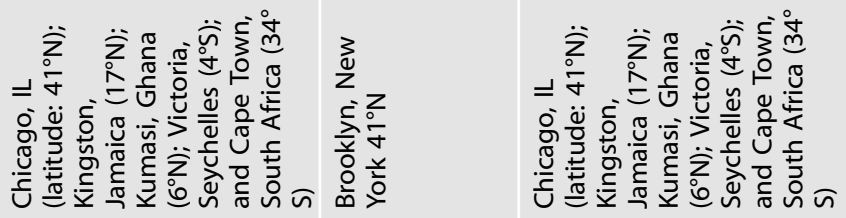

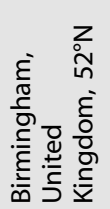
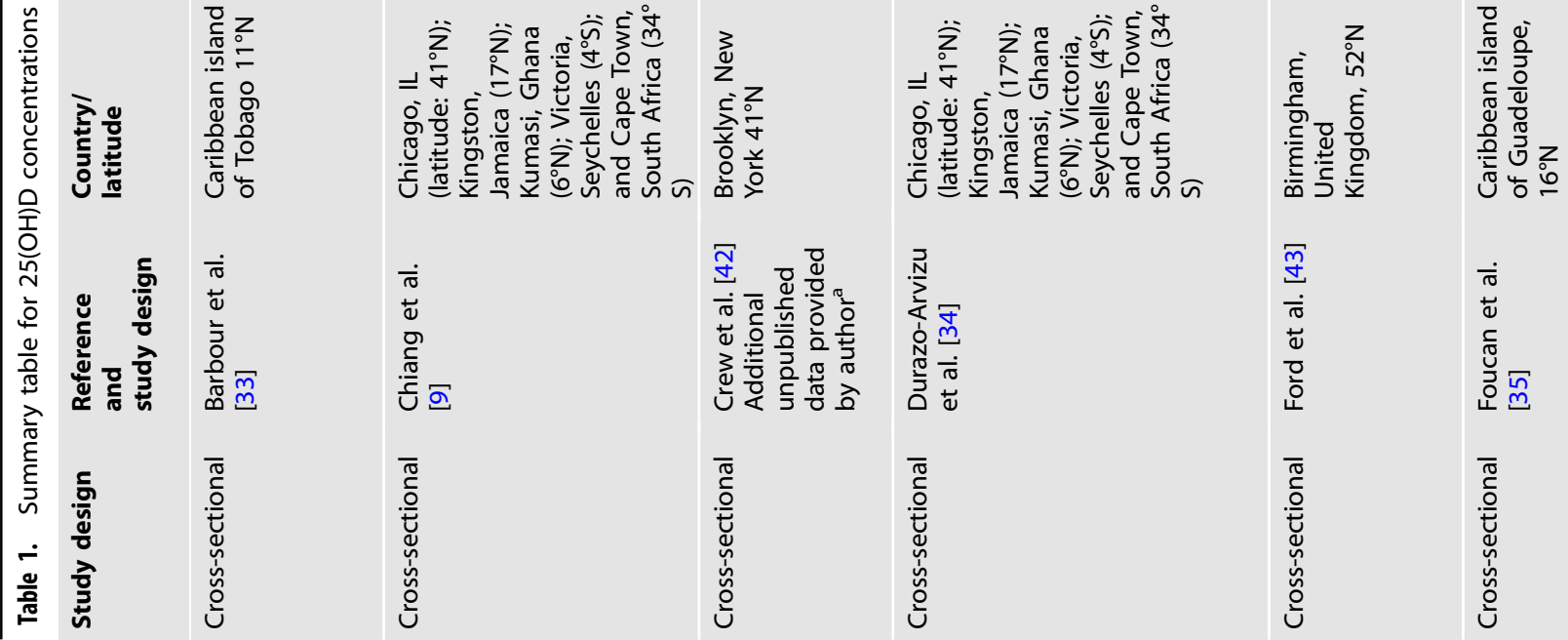

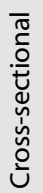

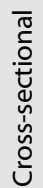




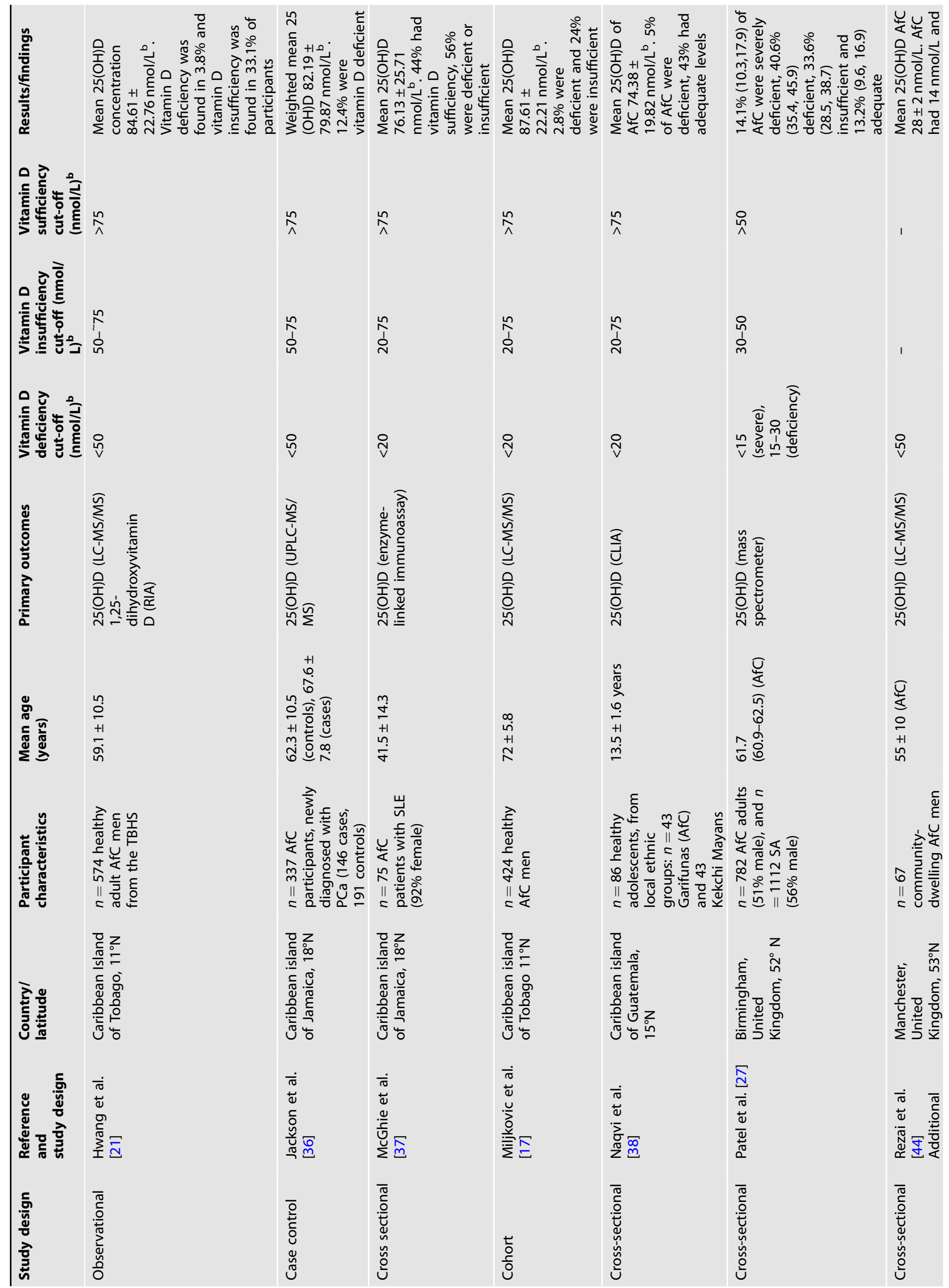


achieve $2.5 \mu \mathrm{g} /$ day [29] (Supplementary File and Table 3). Therefore, dietary intake was compared to the recommendations for the relevant country the study was conducted in.

Data on 25(OH)D concentrations were analysed using units of $\mathrm{nmol} / \mathrm{L}$, and dietary vitamin $D$ intake using $\mu \mathrm{g} /$ day. Where authors reported concentrations in $\mathrm{ng} / \mathrm{mL}$, values were converted to $\mathrm{nmol} / \mathrm{L}$ using a multiple of 2.5 [11]. Where authors reported intake in IU/day, values were multiplied by 0.025 to convert units to $\mu \mathrm{g} /$ day [22].

\section{Quality analysis}

Quality rating of all papers was performed by one author (RMV). The Newcastle Ottawa Scale [30] was used to assess the quality of design and conduct of the case-control studies included in this review. A modified scale adapted by Herzog et al. [31] was used to quality rate cross-sectional and cohort studies [32].

\section{RESULTS}

\section{Systematic review}

The initial search resulted in 2204 papers. After duplicates were removed, 1507 papers were screened by title and abstract. Finally, the full text of 247 papers were screened [23] (See Fig. 1 for PRISMA flow diagram). For reasons for exclusion, see the Supplementary File and Table 4.

Nineteen observational studies, exploring the vitamin D status or dietary intake of the AfC population across six countries with different latitudes were included ( $n=5670$ participants) (see Tables 1 and 2). Jackson et al. [33] reported on both 25(OH)D concentration and dietary intake, so is included in both the 25 $(\mathrm{OH}) \mathrm{D}$ and dietary intake qualitative analyses (see Supplementary File and Table 5). The studies varied in terms of quality, with most studies being considered fair to good quality (Supplementary File and Tables 6 and 7). The included papers were all published in the previous 15 years, from 2005 to 2019 .

\section{5(OH)D concentration of African-Caribbeans living in low latitudes $\left(0-37^{\circ}\right.$ North and South)}

Ten of the included papers explored the 25(OH)D of an AfC population living at low latitudes (Caribbean islands), with high year-round sun exposure ( $n=3209$ participants) [9, 17, 21, 33-39]. All of these studies reported AfC participants to have 'sufficient' vitamin $\mathrm{D}$ levels according to assigned cut-offs, as stated by the study authors. As an exception, Velayoudom-Cephise et al. [39] described their AfC participants with T2DM as having 'insufficient' vitamin D levels, with a mean $25(\mathrm{OH}) \mathrm{D}$ concentration of $54.16 \pm$ $17.22 \mathrm{nmol} / \mathrm{L}$. The study found 'deficiency' ( $<50 \mathrm{nmol} / \mathrm{L})$ in $42.6 \%$ of the population, despite sunny climates [39]. Similarly, Foucan et al. [36] found 'insufficient' ( $<75 \mathrm{nmol} / \mathrm{L}) 25(\mathrm{OH}) \mathrm{D}$ concentration (mean $70.29 \pm 26.51 \mathrm{nmol} / \mathrm{L}$ ) in their population of haemodialysis patients.

AfC populations living close to the equator had higher $25(\mathrm{OH}) \mathrm{D}$ concentrations when compared to their non AfC counterparts $[34,38,39]$. For example, Barbour et al. [34] found AfCs living in the Caribbean had significantly higher 25(OH)D concentrations compared to those with White European ancestry living in the US $(86.61 \pm 24.21$ vs. $68.89 \pm 20.72 \mathrm{nmol} / \mathrm{L}, p<0.001)$. Similarly, Foucan et al. [36] found that AfC dwelling close to the equator had lower rates of vitamin $D$ 'insufficiency' when compared to a previous study with African Americans (AA) living in United States of America (US) (60\% vs $80 \%$ respectively, $p<0.001)$ [40]. Likewise, a study by Naqvi et al. [38] found a higher concentration of $25(\mathrm{OH}) \mathrm{D}$ in AfC compared to the Indigenous Mayan population, living in the Caribbean islands $(74.38 \pm 19.82 \mathrm{nmol} / \mathrm{L}$ vs. $64.47 \pm$ $14.55 \mathrm{nmol} / \mathrm{L}$ ).

Three of these studies reported on the results of the Vitamin D Ancillary Study (VIDA) $[9,35,41]$. This study compared participants of African ancestry living at different latitudes and found, 

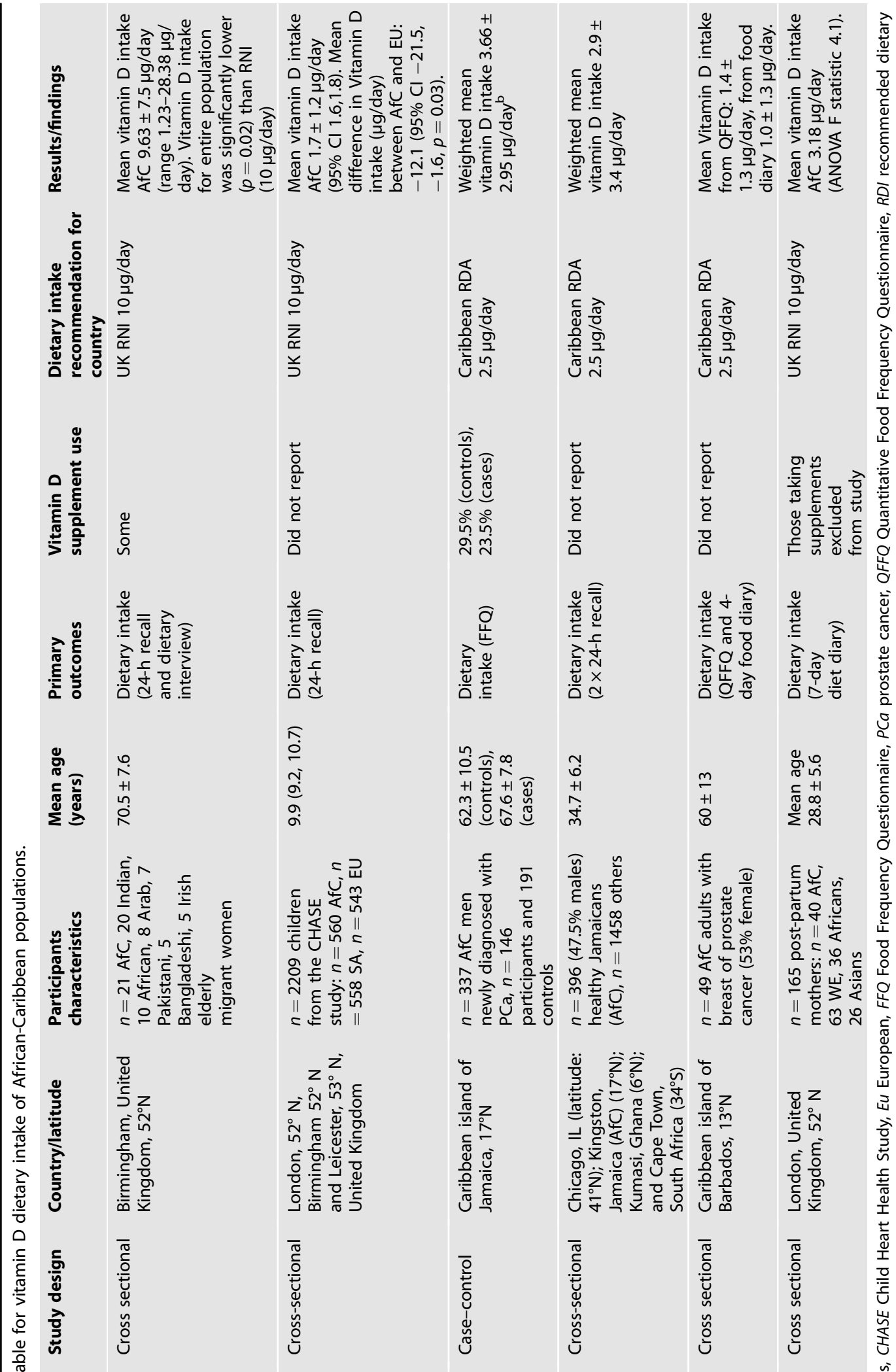

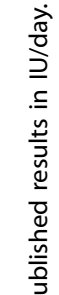

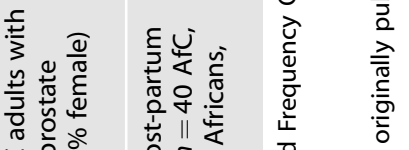

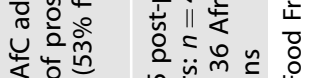

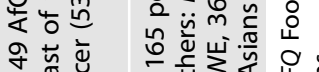

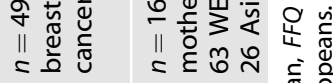

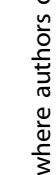


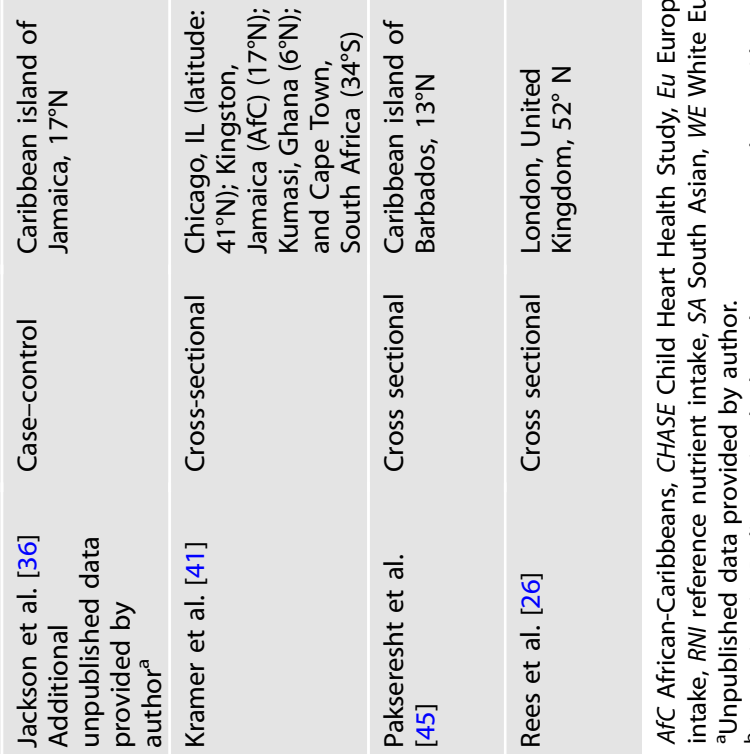

王芯立通

을

U.

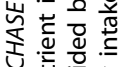

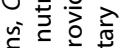

đٓ

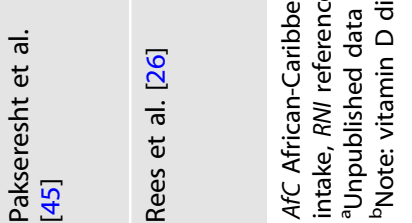




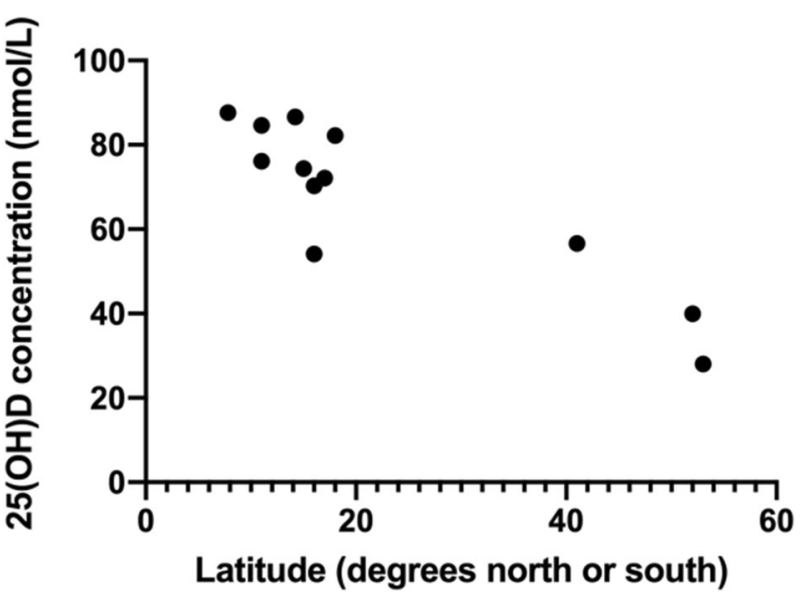

Fig. 2 Relationship between vitamin concentration [25(OH)D] and latitude in the African-Caribbean population. Note: $95 \%$ confidence interval: $-1.210,-0.577, p<0.0001$. Mean $25(\mathrm{OH}) \mathrm{D}$ concentration of $67.8 \mathrm{nmol} / \mathrm{L}, 95 \% \mathrm{Cl}(57.9,77.6)$ from the 12 papers ( $n=2974$, globally) included in the meta-analysis on $25(\mathrm{OH}) \mathrm{D}$ concentration [17, 21, 33-39, 42-44]. Latitude reported by author or estimated. Additional unpublished data was provided by some authors.

according to author defined cut-offs, $90 \%$ of AfC participants living in Jamaica $\left(17^{\circ} \mathrm{N}\right)$ to have 'sufficient' vitamin $\mathrm{D}$ levels, and none to be deficient $[9,35,41]$. Interestingly, they also found, a negative correlation between latitudinal distance from the equator and $25(\mathrm{OH}) \mathrm{D}$ concentrations, with those of African ancestry living in Jamaica $\left(17^{\circ} \mathrm{N}\right)$ having a higher vitamin $\mathrm{D}$ concentration when compared to those with African ancestry living in the US $\left(41^{\circ} \mathrm{N}\right) \quad(72.13 \pm 17.72 \mathrm{nmol} / \mathrm{L}$ vs $42.93 \pm$ $19.96 \mathrm{nmol} / \mathrm{L})[9,35,41]$.

\section{5(OH)D concentration of African-Caribbeans living in mid to} high latitudes (37-90 North and South)

Four studies explored the vitamin D status of AfC populations living at higher latitudes (UK and US) ( $n=995$ participants) $[27,42-44]$. One study was carried out in the US $\left(41^{\circ} \mathrm{N}\right)$ [42], whilst the other three were in the UK $\left(52-53^{\circ} \mathrm{N}\right)[27,43,44]$. In contrast to AfC populations living at low latitudes, these studies found the mean $25(\mathrm{OH}) \mathrm{D}$ concentration of their participants to be 'insufficient' to 'deficient' according to differing author assigned cut-offs, ranging from $28.0 \pm 2.0$ to $56.66 \pm 20.97 \mathrm{nmol} / \mathrm{L}$ [27, 42-44], whilst according to our pre-determined cut-offs, the participants were vitamin D insufficient [27, 43,44] or sufficient [42].

Of the three studies that compared an AfC population to a White Europeans (WE) population, living in the same location, found higher concentrations of $25(\mathrm{OH}) \mathrm{D}$ in the WE population [42-44]. Crew et al. [42] found that higher levels of 25(OH)D were associated with WE ethnicity. Ford et al. [43] reported that WE had the highest mean levels of $25(\mathrm{OH}) \mathrm{D}$, followed by AfCs and then South Asians. Of note, this study also showed that one in every four AfCs living in the UK $\left(52^{\circ} \mathrm{N}\right)$ were vitamin $D$ 'deficient', according to the author's definition $(<25 \mathrm{nmol} / \mathrm{L})$ after summer [43]. Likewise, Rezai et al. [44] reported a deficient $(<50 \mathrm{nmol} / \mathrm{L})$ mean $25(\mathrm{OH}) \mathrm{D}$ of $28 \pm 2 \mathrm{nmol} /$ in their AfC sample, which was a $14 \mathrm{nmol} / \mathrm{L}$ lower than the mean concentration of their WE counterparts $(p<0.001)$. Patel et al. [27] found that only $15.4 \%$ of AfC participants living in the UK had adequate vitamin D levels (defined as $>50 \mathrm{nmol} / \mathrm{L}$ ).

We found a strong inverse association (Pearson's correlation) between $25(\mathrm{OH}) \mathrm{D}$ status and distance from the equator $(r=$ $-0.894, p<0.0001)$ across the 12 papers [17, 21, 33-39, 42-44] included in the sub sample that measured $25(\mathrm{OH}) \mathrm{D}$ at different latitudes (Fig. 2).

\section{Vitamin D dietary intake at low latitudes $0-37^{\circ}$ North and South}

Three studies measured vitamin D dietary intake in AfC populations living close to the equator (Caribbean islands) $(n=782$ participants) $[33,41,45]$. The studies varied in terms of the tools used to measure intake, including food frequency questionnaire [33, 45], a $24 \mathrm{~h}$ food recall [41] and a 4-day food diary [45]. The Caribbean islands have a low recommended dietary allowance (RDA) for vitamin D of $2.5 \mu \mathrm{g} /$ day [29]. Although intakes were low, ranging from 1.0 to $3.7 \mu \mathrm{g} /$ day of vitamin $D$, two studies had 'sufficient' mean intakes when compared to the local RDA for this population $[33,41]$. However, in another study, the mean intake of vitamin D for Caribbean island participants with breast or prostate cancer did not meet recommendations [45]. This may be partly explained by the fact that these research participants had cancer, so may not have had normal food intake.

Vitamin D dietary intake at high latitudes $37-90^{\circ}$ North and South

Three studies measured dietary intake of vitamin $D$ at high latitudes (all in the UK) ( $n=621$ participants) $[26,46,47]$. All studies included used a 24-h recall to assess dietary intake $[26,47]$, whilst in addition, Castaneda-Gameros et al.[46] also used a dietary review. The UK recommended nutrient intake (RNI) for vitamin $D$ is $10 \mu \mathrm{g} /$ day [22]. Low vitamin $D$ dietary intake was seen in all the studies, ranging from 1.7 to $9.6 \mu \mathrm{g} /$ day. A study of $n=40$ post-partum mothers by Rees et al. [26], found that AfC women living in the UK, although having low intakes of vitamin $D$, still reported slightly higher mean intakes than those of WE or Asian ancestry. Conversely, in another study, inadequate dietary vitamin $D$ was seen in AfC children $(1.71 \mu \mathrm{g} /$ day $)$, with intakes lower than that of their WE counterparts $(1.9 \mu \mathrm{g} /$ day $)$, but higher than those of South Asian children $(1.4 \mu \mathrm{g} /$ day) [47]. A small study by Castaneda-Gameros et al. in older migrant women of mixed ethnicity found vitamin $D$ to be a nutrient of concern, with a median intake of $2.6 \mu \mathrm{g} /$ day (IQR 0.7-11.4), significantly lower than the UK RNI $(p=0.02)$. However, in a sub sample $(n=21)$ of AfC women, in the same study, unpublished data provided by the authors showed a mean intake of $9.6 \mu \mathrm{g} / \mathrm{day}$ vitamin D, which, included participants who used vitamin D containing supplements [46].

\section{Meta-analysis}

Sixteen studies were included in the meta-analysis, which involved analysis of $25(\mathrm{OH}) \mathrm{D}$ concentration [17, 21, 33-39, 42-44] and vitamin D dietary intake [33, 41,45-47] of AfC populations living at different latitudes. Jackson et al. [33] reported on both 25(OH)D and dietary intake. The remaining three studies were excluded due to insufficient data $[26,27]$ or reporting on the same data as another author, in which case the study published first was used [9].

\section{5(OH)D concentration}

Twelve studies reported 25(OH)D concentration $(n=2974$ participants) $[17,21,33-39,42-44]$. The pooled effect size for 25(OH)D concentration in AfC populations was a mean (random) of $67.8 \mathrm{nmol} /$ $\mathrm{L}, 95 \% \mathrm{Cl}(57.9,77.6)$, with statistically significant heterogeneity $\left(P_{\text {(heterogeneity) }}<0.001\right)$. A pooled mean (fixed) of $73.5 \mathrm{nmol} / \mathrm{L}, 95 \% \mathrm{Cl}$ $(72.7,74.3)$ with statistically significant heterogeneity $\left(P_{\text {(heterogeneity) }}\right.$ $<0.001$ ) was found in a fixed effects model.

A meta-analysis of $25(\mathrm{OH}) \mathrm{D}$ concentration in AfC populations living at high latitudes $[27,42-44]$ resulted in a pooled mean (random) $_{\text {. }}$ of $40.9 \mathrm{nmol} / \mathrm{L}, 95 \% \mathrm{Cl}(28.1,53.7)$ and a pooled mean (fixed) of $36.0 \mathrm{nmol} / \mathrm{L}, 95 \% \mathrm{Cl}(33.4,38.7)$. At low latitudes [9, 17, 21, 33-39], a pooled mean $_{\text {(random) }}$ of $76.4 \mathrm{nmol} / \mathrm{L}, 95 \% \mathrm{Cl}(68.6,84.3)$ and a pooled mean (fixed) of $77.3 \mathrm{nmol} / \mathrm{L}, 95 \% \mathrm{Cl}(76.5,78.1)$ was found. Statistically significant heterogeneity was present in all models $(p<0.001)$ (see Fig. 3 for random effects models, and Supplementary File and Fig. 1 for fixed effects models). 
A

25(OH)D nmol/L by study- random effects

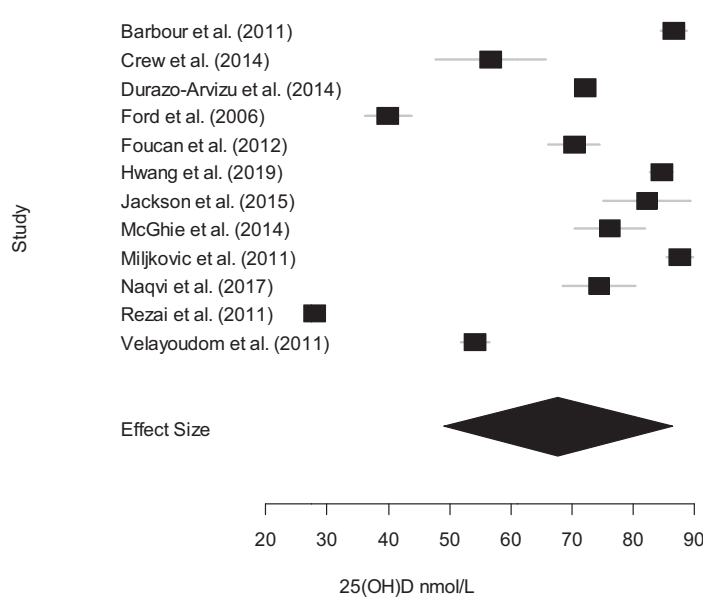

C

25(OH)D nmol/L by study- random effects

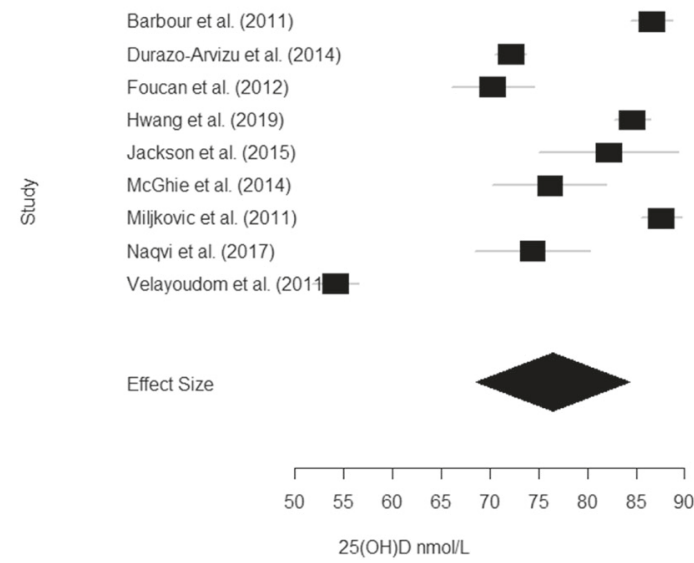

B

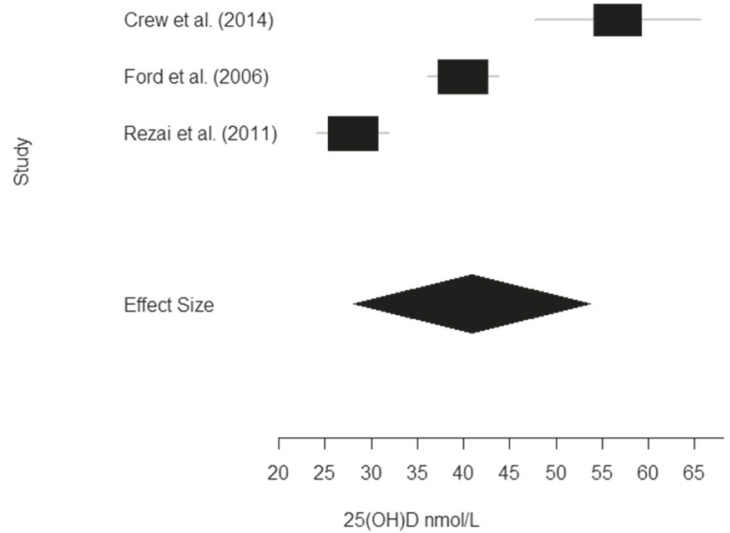

Fig. 3 Random effects meta-analyses of 25(OH)D concentration of the African-Caribbean population. A All countries: summary effect $=$ $67.8 \mathrm{nmol} / \mathrm{L}, 95 \% \mathrm{Cl}(57.9,77.6)(n=2974$ participants). B High latitudes: summary effect $=40.9 \mathrm{nmol} / \mathrm{L}, 95 \% \mathrm{Cl}(28.1,53.7)(n=213$ participants). C Low latitudes summary effect $=76.4 \mathrm{nmol} / \mathrm{L}, 95 \% \mathrm{Cl}(68.6,84.3)(n=2761$ participants). Estimated heterogeneity for all analyses was $p<0.001$.

\section{Vitamin D dietary intake}

Five studies reported on vitamin D dietary intake $(n=1363$ participants) $[33,41,45-47]$. The pooled mean (random) $_{\text {effect size }}$ for vitamin D dietary intake was $3.0 \mu \mathrm{g} /$ day, $95 \% \mathrm{Cl}(1.67,4.31)$ with statistically significant heterogeneity $\left(P_{(\text {heterogeneity })}<0.001\right)$. In a fixed effect model, a pooled mean (fixed) of $1.84 \mu \mathrm{g} /$ day, $95 \% \mathrm{Cl}(1.75$, $1.93)$ with statistically significant heterogeneity $\left(P_{\text {(heterogeneity })<}\right.$ 0.001) was found.

For vitamin $D$ intakes in populations living at high latitudes $[46,47]$, there was a pooled $\operatorname{mean}_{\text {(random) }}$ of $5.51 \mu \mathrm{g} /$ day, $95 \% \mathrm{Cl}$ $(-2.26,13.3)$ and a pooled mean $_{\text {(fixed) }}$ of $1.71 \mu \mathrm{g} /$ day, $95 \% \mathrm{Cl}(1.61$, 1.81). At low latitudes $[33,41,45]$ a pooled mean $_{\text {(random) }}$ of $2.38 \mu \mathrm{g} /$ day, $95 \% \mathrm{Cl}(-0.112,4.87)$ and a pooled mean (fixed) of $2.68 \mu \mathrm{g} /$ day, $95 \% \mathrm{Cl}(2.43,2.93)$ was found. Statistically significant heterogeneity was present in all sub-group models $(p<0.001)$. A sensitivity analysis showed consistent results across all analyses (see Fig. 4 for random effects models, and Supplementary File and
Fig. 2 for fixed effects models and Table 8 for the sensitivity analysis).

\section{DISCUSSION}

This systematic review and meta-analysis assessed the vitamin $D$ status of AfC populations globally. A random effects meta-analysis found this population, as a whole, to have sufficient (based on our cut-offs: sufficiency $>50 \mathrm{nmol} / \mathrm{L}$ [28]) mean $25(\mathrm{OH}) \mathrm{D}$ concentration at $67.8 \mathrm{nmol} / \mathrm{L}$, yet had low mean dietary intakes of vitamin $\mathrm{D}$ at only $3.0 \mu \mathrm{g} /$ day.

However, vitamin D status varied by latitude. We found higher 25(OH)D concentrations in AfC populations living at lower latitudes, compared with higher latitudes. First, using simple correlation, we found a strong inverse association between $25(\mathrm{OH})$ $\mathrm{D}$ status and distance from the equator. Second, random effects meta-analyses showed a mean $25(\mathrm{OH}) \mathrm{D}$ concentration at low 


\section{A}

Vitamin $D$ intake (micrograms/d) by study- random effects
B

Vitamin D intake (micrograms/d) by study- random effects

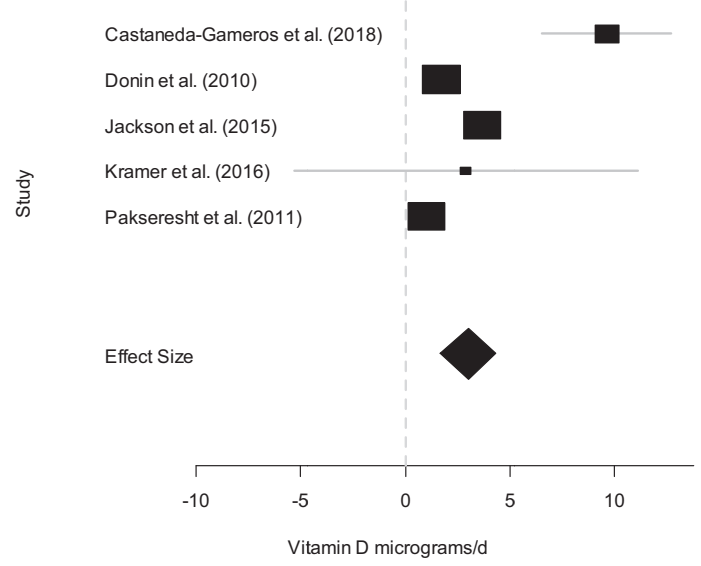

C
Castaneda-Gameros et al. (2018)

Donin et al. (2010)

\begin{tabular}{|c|c|c|c|c|c|}
\hline 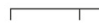 & 1 & 1 & 1 & $T$ & $T$ \\
\hline 2 & 4 & 6 & 8 & 10 & 12 \\
\hline
\end{tabular}

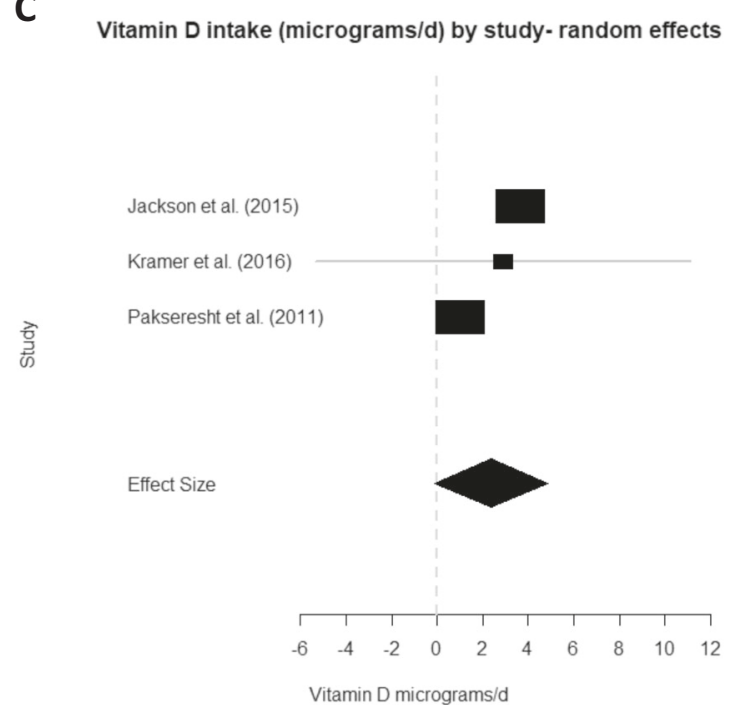

Fig. 4 Random effects meta-analyses of vitamin D intake of the African-Caribbean population. A All countries: summary effect $=2.99 \mu \mathrm{g} / \mathrm{day}$, $95 \% \mathrm{Cl}(1.67,4.31)$ ( $n=1363$ participants). B High latitudes: summary effect $=5.51 \mu \mathrm{g} /$ day, $95 \% \mathrm{Cl}(-2.26,13.3)(n=581$ participants). C Low latitudes: summary effect $=2.38 \mu \mathrm{g} / \mathrm{day}, 95 \% \mathrm{Cl}(-0.112,4.87)(n=782$ participants). Estimated heterogeneity for all analyses was $p<0.001$.

latitudes of $76.4 \mathrm{nmol} / \mathrm{L}$, which would be classified as sufficient (>50 nmol/L [28]). However, meta-analyses showed that populations at high latitudes had insufficient concentrations, with a mean 25(OH)D concentration of $40.9 \mathrm{nmol} / \mathrm{L}$. Random effects meta-analyses for vitamin D intake also showed a latitude differential. For high latitudes, intakes were $5.5 \mu \mathrm{g} /$ day. Equivalent intakes for low latitudes were $2.4 \mu \mathrm{g} /$ day.

Of note, our sensitivity analyses showed consistent metaanalysis findings for both $25(\mathrm{OH}) \mathrm{D}$ concentration and vitamin $\mathrm{D}$ dietary intake, suggesting the analyses were robust.

We can speculate as to why AfC populations living at higher latitudes have poorer vitamin $D$ status than do those at lower latitudes. Populations residing closer to the equator have an abundance of annual sunshine hours, and greater ability to synthesise vitamin D from intense UVB radiation due to the zenith angle of the sun $[11,36]$. Accordingly, the studies included in this review all found vitamin $D$ sufficiency in populations living at these low latitudes. As an exception, 'insufficient' 25(OH)D levels were found only in participants from two studies [36, 39].
However, vitamin D cut-offs applied in these studies were high $(<75 \mathrm{nmol} / \mathrm{L})$ and when compared to our cut-offs, these participants were sufficient $(>50 \mathrm{nmol} / \mathrm{L})$. Additionally, these participants either had T2DM or were people with chronic renal disease that were undergoing haemodialysis [36, 39], both of which are associated with vitamin $\mathrm{D}$ deficiency.

Our findings are similar to those from studies of other ethnic minorities living at high latitudes. For example, South Asian populations living in the UK are known to have high levels of vitamin $D$ deficiency $(<25 \mathrm{nmol} / \mathrm{L})$ [48]. Our findings suggest that the extent of vitamin $D$ deficiency, although higher than in WE, may not be as extensive as those seen in the South Asian population.

Vitamin D intake was low in AfC populations across all latitudes. However, when considering the different dietary recommendations by country, suboptimal intakes were more common at high latitudes, that is, the UK [22]. The highest intake of vitamin D in the UK was found in a small sub-sample of a study by CastanedaGameros et al. [22, 46], this may be due, in part, to some participants taking supplements that may have artificially elevated 
their vitamin D intakes [46]. Interestingly, those UK participants who took vitamin $\mathrm{D}$ and calcium supplements met the recommended nutrient intake (RNI) for both nutrients, suggesting a supplement may be needed for AfC to meet recommendations at this latitude, with its recognised lower sunlight levels $[22,46]$. Closer to the equator, adherence to locally recommended dietary intakes (RDI) was achieved in two out of three studies $[33,41]$ but is likely attributed to lower RDI recommendations in the countries studied which take into consideration the abundance of sunshine seen in these countries [29].

The findings of this review suggest that awareness of vitamin $D$ deficiency needs to be raised amongst AfC populations living at higher latitudes. Furthermore, vitamin D deficiency should also be of concern at lower latitudes, as although deficiency rates are lower, sufficient sun exposure may be difficult for some to achieve and others may be predisposed to deficiency due to associated chronic conditions $[49,50]$. The trend for low dietary vitamin $D$ intake has led to recommendations to consume vitamin $\mathrm{D}$ rich foods, fortified products, and to consider taking supplements, especially for those living at higher latitudes where there is greater risk of vitamin D deficiency [22]. This may be of importance to scientists, policy makers and clinicians working in these higher latitude countries, as very little is known in relation to the extent of deficiency, as well as strategies to address deficiency in this population group. The findings of our review highlight a need for education on the importance of vitamin $D$, whilst further research is needed on the impact of vitamin $D$ deficiency in AfC populations.

Strengths of this review are that it provides a novel focus on the AfC population and illustrates vitamin D status is associated with latitude of residence. However, this review does have some limitations. Firstly, the health of the populations varied between studies, with some populations having pre-existing medical conditions that may exacerbate vitamin D deficiency. Also, all of the high latitude studies were from the UK and the US, which limits generalisability of the results. Additionally, those who selfidentified as African-Caribbean, may have been of mixed race which could have impacted on their vitamin D status, due to variations in skin colour.

The methods used to analyse $25(\mathrm{OH}) \mathrm{D}$ concentration and dietary vitamin $\mathrm{D}$ intake also varied between studies. Some studies on black populations, which could have included AfC, may have been unnecessarily excluded due to insufficient information about participant sub-ethnicity. The use of vitamin D supplements was also not recorded in all studies, which may too have impacted on results. Converting skewed data from median and IQR to mean and SD to perform the meta-analysis may have limited the accuracy of the results. The Newcastle Ottawa Scale was not a good fit to all studies, especially for case-control studies which had to be analysed using the adapted scale. Therefore, this subjective process was used as a general guide to assess quality, rather than providing a definitive score.

\section{CONCLUSION}

This systematic review and meta-analysis found sufficient vitamin $D$ levels in AfC populations as a whole, however vitamin D insufficiency was still prevalent in AfC populations living in higher latitude countries. Dietary intake of vitamin D in AfC populations was low, globally; although populations in lower latitude countries were meeting local intake guidelines. These findings highlight a need, particularly in higher latitude countries, for public health and clinical action to improve the vitamin $\mathrm{D}$ awareness and status of AfC populations. This could include strategies to increase vitamin $D$ intake, as well as the use of safe sunlight exposure, as appropriate. Further studies on the association between vitamin D and health outcomes, using larger sample sizes, is needed in this population, especially at higher latitudes.

\section{REFERENCES}

1. Chen TC, Chimeh F, Lu Z, Mathieu J, Person KS, Zhang A, et al. Factors that influence the cutaneous synthesis and dietary sources of vitamin D. Arch Biochem Biophys. 2007;460:213-7.

2. Jones G. Pharmacokinetics of vitamin D toxicity. Am J Clin Nutr. 2008;88:582s-6s.

3. Prentice A, Schoenmakers I, Jones KS, Jarjou LMA, Goldberg GR. Vitamin D deficiency and its health consequences in Africa. Clin Rev Bone Miner Metab. 2009;7:94-106.

4. Durazo-Arvizu RA, Pacheco-Dominguez RL, Sempos $C T$, Kramer $\mathrm{H}$, Hoofnagle $A N$, Pirzada $A$, et al. The association between cardiovascular disease risk factors and 25-hydroxivitamin $D$ and related analytes among hispanic/latino adults: a pilot study. Nutrients. 2019;11:1959.

5. Bellavia D, Costa V, De Luca A, Maglio M, Pagani S.Fini M, Vitamin D level between calcium-phosphorus homeostasis and immune system: new perspective in osteoporosis. Curr Osteoporos Rep. 2016;1-12. https://doi.org/ 10.1007/s11914-016-0331-2.

6. Nair R, Maseeh A. Vitamin D: the "sunshine" vitamin. J Pharmacol Pharmacother 2012;3:118-26.

7. Cashman KD. Vitamin D deficiency: defining, prevalence, causes, and strategies of addressing. Calcif Tissue Int. 2019;106:14-29.

8. Martins JS, MdO Palhares, Teixeira OCM, Ramos MG. Vitamin D status and its association with parathyroid hormone concentration in Brazilians. J Nutr Metab. 2017:2017:9056470-

9. Chiang D, Kramer H, Luke A, Cooper R, Aloia J, Bovet P, et al. 25-Hydroxyvitamin D and blood pressure: a plateau effect in adults with African ancestry living at different latitudes. J Hypertension. 2017;35:968-74.

10. Christakos S, Dhawan P, Verstuyf A, Verlinden L, Carmeliet G. Vitamin D: metabolism, molecular mechanism of action, and pleiotropic effects. Physiol Rev. 2016;96:365-408.

11. Wacker M, Holick MF. Sunlight and vitamin D: a global perspective for health. Derm-Endocrinology. 2013;5:51-108.

12. Mangin $M$, Sinha $R$, Fincher K. Inflammation and vitamin $D$ : the infection connection. Inflamm Res. 2014;63:803-19.

13. Duan S, Lv Z, Fan X, Wang L, Han F, Wang H, et al. Vitamin D status and the risk of multiple sclerosis: a systematic review and meta-analysis. Neurosci Lett. 2014;570:108-13.

14. Aranow C. Vitamin D and the immune system. J Investig Med. 2011;59:881-6.

15. Prentice A. Vitamin D deficiency: a global perspective. Nutr Rev 2008;66:S153-64

16. Sakamoto R, Jaceldo-Siegl K, Haddad E, Oda K, Fraser GE, Tonstad S. Relationship of vitamin $D$ levels to blood pressure in a biethnic population. Nutr Metab Cardiovasc Dis. 2013;23:776-84.

17. Miljkovic I, Bodnar LM, Cauley JA, Bunker CH, Patrick AL, Wheeler VW, et al. Low prevalence of vitamin D deficiency in elderly Afro-Caribbean men. Ethnicity Dis. 2011;21:79-84

18. Wilson LR, Tripkovic L, Hart KH, Lanham-New SA. Vitamin D deficiency as a public health issue: using vitamin D2 or vitamin D3 in future fortification strategies. Proc Nutr Soc. 2017;76:392-9.

19. Agyemang C, Bhopal R, Bruijnzeels M. Negro, Black, Black African, African Caribbean, African American or what? Labelling African origin populations in the health arena in the 21st century. J Epidemiol Community Health. 2005;59:1014.

20. Jablonski NG, Chaplin G. The evolution of human skin coloration. J Hum Evol. 2000;39:57-106.

21. Hwang J, Zmuda JM, Kuipers AL, Bunker CH, Santanasto AJ, Wheeler VW, et al. Serum vitamin $D$ and age-related muscle loss in Afro-Caribbean Men: the importance of age and diabetic status. J Frailty Aging 2019;8:131-7.

22. Scientific Advisory Committee on Nutrition. Vitamin D and Health. 2016. Scientific Advisory Committee on Nutrition (2016) Vitamin D and Health. https://www.gov. uk/government/publications/sacn-vitamin-d-and-health-report.

23. Moher D, Liberati A, Tetzlaff J, Altman DG. Preferred reporting items for systematic reviews and meta-analyses: the PRISMA statement. BMJ 2009;339:b2535.

24. Package 'rmeta'. Lumley T rmeta package version 3. 2018. https://cran.r-project. org/web/packages/rmeta/rmeta.pdf.

25. Wan X, Wang W, Liu J, Tong T. Estimating the sample mean and standard deviation from the sample size, median, range and/or interquartile range. BMC Med Res Methodol. 2014;14:135.

26. Rees GA, Doyle W, Srivastava A, Brooke ZM, Crawford MA, Costeloe KL. The nutrient intakes of mothers of low birth weight babies - a comparison of ethnic groups in East London, UK. Matern Child Nutr. 2005;1:91-9.

27. Patel JV, Chackathayil J, Hughes EA, Webster C, Lip GYH, Gill PS. Vitamin D deficiency amongst minority ethnic groups in the UK: a cross sectional study. Int J Cardiol. 2013;167:2172-6.

28. Institute of Medicine (US) Committee to Review Dietary Reference Intakes for Vitamin D and Calcium, Ross, A. C., Taylor, C. L., Yaktine, A. L., \& Del Valle, H. B. (Eds.). (2011). Dietary Reference Intakes for Calcium and Vitamin D. National Academies Press (US). 
29. Caribbean Food and Nutrition Institute. Recommended Dietary Allowances for the Caribbean - Report of the Comittee of the Expert Group on Caribbean Food and Nutrition Survelliance System Mona, Kingston:Caribbean Food and Nutrition Institute; 1994.

30. Wells G, Shea B, O'Connell D, Peterson J, Welch V, Losos M, et al. The NewcastleOttawa Scale (NOS) for assessing the quality of nonrandomised studies in metaanalyses. 2014. http://www.ohri.ca/programs/clinical_epidemiology/oxford.asp.

31. Herzog R, Álvarez-Pasquin MJ, Díaz C, Del Barrio JL, Estrada JM, Gil Á. Are healthcare workers' intentions to vaccinate related to their knowledge, beliefs and attitudes? a systematic review. BMC Public Health. 2013;13:154.

32. Modesti PA, Reboldi G, Cappuccio FP, Agyemang C, Remuzzi G, Rapi S, et al. Panethnic differences in blood pressure in Europe: a systematic review and metaanalysis. PLoS ONE. 2016;11:e0147601.

33. Jackson MD, Tulloch-Reid MK, Lindsay CM, Smith G, Bennett Fl, McFarlaneAnderson $\mathrm{N}$, et al. Both serum 25-hydroxyvitamin $\mathrm{D}$ and calcium levels may increase the risk of incident prostate cancer in Caribbean men of African ancestry. Cancer Med. 2015:4:925-35.

34. Barbour KE, Zmuda JM, Horwitz MJ, Strotmeyer ES, Boudreau R, Evans RW, et al. The association of serum 25-hydroxyvitamin $D$ with indicators of bone quality in men of Caucasian and African ancestry. Osteoporos Int. 2011;22:2475-85.

35. Durazo-Arvizu RA, Camacho P, Bovet P, Forrester T, Lambert EV, Plange-Rhule J, et al. 25-Hydroxyvitamin $D$ in African-origin populations at varying latitudes challenges the construct of a physiologic norm. Am J Clin Nutr. 2014;100:908-14.

36. Foucan L, Ducros J, Merault H. Vitamin D status in dark-skinned patients undergoing hemodialysis in a continually sunny country. J Nephrol. 2012;25:983-8.

37. McGhie TK, DeCeulaer K, Walters CA, Soyibo A, Lee MG. Vitamin D levels in Jamaican patients with systemic lupus erythematosus. Lupus 2014;23:1092-6.

38. Naqvi A, Solomons NW, Campos R, Soto-Mendez MJ, Caplan E, Armas L, et al. Vitamin D status among indigenous Mayan (Kekchi) and Afro-Caribe (Garifuna) adolescents from Guatemala: a comparative description between two ethnic groups residing on the Rio Dulce at the Caribbean coast in Izabal Province, Guatemala. Public Health Nutr. 2017;20:1729-37.

39. Velayoudom-Cephise FL, Larifla L, Donnet JP, Maimaitiming S, Deloumeaux J, Blanchet $A$, et al. Vitamin $D$ deficiency, vitamin $D$ receptor gene polymorphisms and cardiovascular risk factors in Caribbean patients with type 2 diabetes. Diabetes Metab. 2011;37:540-5.

40. Wolf $M$, Betancourt J, Chang $Y$, Shah A, Teng $M$, Tamez $H$, et al. Impact of activated vitamin $D$ and race on survival among hemodialysis patients. J Am Soc Nephrol. 2008;19:1379-88.

41. Kramer H, Camacho $P$, Aloia J, Luke A, Bovet $P$, Rhule JP, et al. Association between 25-Hydroxyvitamin $D$ and intact parathyroid hormone levels across latitude among adults with African ancestry. Endocr Pract. 2016;22:911-9.

42. Crew KD, Campbell J, Reynolds D, Fulton L, Flom JD, Liao YY, et al. Mammographic density and serum 25-hydroxyvitamin D levels. Nutr Metab. 2014;11:18.

43. Ford L, Graham V, Wall A, Berg J. Vitamin D concentrations in an UK inner-city multicultural outpatient population. Ann Clin Biochem. 2006;43:468-73.

44. Rezai MR, Wallace AM, Sattar N, Finn JD, Wu FC, Cruickshank JK. Ethnic differences in aortic pulse wave velocity occur in the descending aorta and may be related to vitamin D. Hypertension 2011;58:247-53.

45. Pakseresht M, Sharma S, Cao X, Harris R, Caberto C, Wilkens LR, et al. Validation of a quantitative FFQ for the Barbados National Cancer Study. Public Health Nutr. 2011;14:426-34.

46. Castaneda-Gameros D, Redwood S, Thompson JL. Nutrient intake and factors influencing eating behaviors in older migrant women living in the United Kingdom. Ecol Food Nutr. 2018;57:50-68.

47. Donin AS, Nightingale CM, Owen CG, Rudnicka AR, McNamara MC, Prynne CJ, et al. Nutritional composition of the diets of South Asian, black African-Caribbean and white European children in the United Kingdom: The Child Heart and Health Study in England (CHASE). Br J Nutr. 2010;104:276-85.

48. Darling AL, Blackbourn DJ, Ahmadi KR, Lanham-New SA. Vitamin D supplement use and associated demographic, dietary and lifestyle factors in 8024 South Asians aged 40-69 years: analysis of the UK Biobank cohort. Public Health Nutr. 2018;21:2678-88.

49. Unger MD, Cuppari L, Titan SM, Magalhães MCT, Sassaki AL, dos Reis $L M$, et al. Vitamin D status in a sunny country: Where has the sun gone? Clin Nutr. 2010;29:784-8
50. Wang H, Chen W, Li D, Yin X, Zhang X, Olsen N, et al. Vitamin D and chronic diseases. Aging Dis. 2017;8:346-53.

\section{ACKNOWLEDGEMENTS}

We thank Crew et al., Rezai et al., Castaneda-Gameros et al. and Jackson et al. for providing additional unpublished data on the vitamin D status of their populations for inclusion in this review.

\section{AUTHOR CONTRIBUTIONS}

RMV has first authorship and is the guarantor. RMV, ALD, KHH and SALN designed the study. RMV search the databases and screened papers for inclusion, ASO screened a random sample. RMV and ALD interpreted and analysed the data. JM contributed to statistical support in terms of R code. RMV, KHH, ALD, SALN, KC and YP drafted the manuscript. All authors reviewed and approved the final manuscript and are accountable for all aspects of the work. The corresponding author attests that all listed authors meet authorship criteria and that no others meeting the criteria have been omitted.

\section{FUNDING}

This work is part of the PhD of RMV, which is funded by the Universities Global Partnership Network, co-supervised by the Universities of Surrey and Wollongong. Funders did not have a role in the study. The researchers are independent to the funders, whilst all authors had full access to data and take responsibility for the integrity of the data and the accuracy of the data analysis.

\section{CONFLICT OF INTEREST}

All authors have no conflict of interest to disclose, except SALN who reports honoraria for three conference talks from Thornton \& Ross and one from the Council for Responsible Nutrition, consultancy for General Mills and is research Director of D3Tex Ltd which holds the UK and GCC Patent for the use of materials for vitamin D prevention in populations who dress for cultural style.

\section{ADDITIONAL INFORMATION}

Supplementary information The online version contains supplementary material available at https://doi.org/10.1038/s41430-021-00980-9.

Correspondence and requests for materials should be addressed to R.M.V.

Reprints and permission information is available at http://www.nature.com/ reprints

Publisher's note Springer Nature remains neutral with regard to jurisdictional claims in published maps and institutional affiliations.

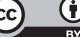

Open Access This article is licensed under a Creative Commons Attribution 4.0 International License, which permits use, sharing, adaptation, distribution and reproduction in any medium or format, as long as you give appropriate credit to the original author(s) and the source, provide a link to the Creative Commons license, and indicate if changes were made. The images or other third party material in this article are included in the article's Creative Commons license, unless indicated otherwise in a credit line to the material. If material is not included in the article's Creative Commons license and your intended use is not permitted by statutory regulation or exceeds the permitted use, you will need to obtain permission directly from the copyright holder. To view a copy of this license, visit http://creativecommons. org/licenses/by/4.0/.

(c) The Author(s) 2021 